\title{
Enzyme Kinetics of Organic Contaminant Oxygenations
}

\author{
Charlotte E. Bopp ${ }^{\text {ab }}$, Hans-Peter E. Kohlerab, and Thomas B. Hofstetter ${ }^{\star a b}$
}

\begin{abstract}
Enzymatic oxygenations initiate biodegradation processes of many organic soil and water contaminants. Even though many biochemical aspects of oxygenation reactions are well-known, quantifying rates of oxidative contaminant removal as well as the extent of oxygenation remains a major challenge. Because enzymes use different strategies to activate $\mathrm{O}_{2}$, reactions leading to substrate oxygenation are not necessarily limiting the rate of contaminant removal. Moreover, oxygenases react along unproductive pathways without substrate metabolism leading to $\mathrm{O}_{2}$ uncoupling. Here, we identify the critical features of the catalytic cycles of selected oxygenases that determine rates and extents of biodegradation. We focus most specifically on Rieske dioxygenases, a subfamily of mononuclear non-heme ferrous iron oxygenases, because of their ability to hydroxylate unactivated aromatic structures and thus initiate the transformation of the most persistent organic contaminants. We illustrate that the rate-determining steps in their catalytic cycles range from $\mathrm{O}_{2}$ activation to substrate hydroxylation, depending on the extent of $\mathrm{O}-\mathrm{O}$ cleavage that is required for generating the reactive $\mathrm{Fe}$-oxygen species. The extent of $\mathrm{O}_{2}$ uncoupling, on the other hand, is highly substrate-specific and potentially modulated by adaptive responses to oxidative stress. Understanding the kinetic mechanisms of oxygenases will be key to assess organic contaminant biotransformation quantitatively.
\end{abstract}

Keywords: Biodegradation · Catalytic cycles $\cdot$ Non-heme Fell oxygenases $\cdot \mathrm{O}_{2}$ uncoupling

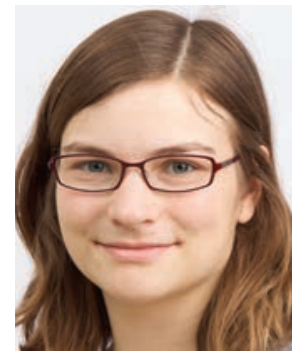

Charlotte Bopp is a $\mathrm{PhD}$ student under the supervision of Thomas Hofstetter and Hans-Peter Kohler at Eawag and ETH Zurich. She studies nitroarene dioxygenases using compound-specific isotope analysis to elucidate their catalytic cycles and track their activity in the field. She received her Masters degree in Environmental Sciences with a major in Biogeochemistry and Pollutant Dynamics at ETH Zurich.

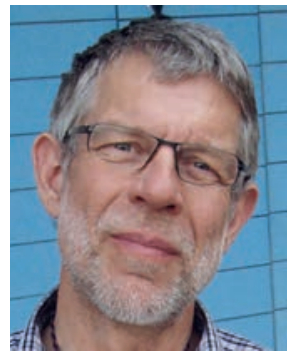

Hans-Peter Kohler is a senior scientist at the Department of Environmental Microbiology at Eawag. He studied Biochemistry at ETH Zurich and earned his $\mathrm{PhD}$ in Microbiology at ETH in 1986. He was a postdoctoral researcher at the University of California and a visiting research professor at the Department of Microbiology and the Center for Global and Regional Environmental Research (CGRER) at the University of Iowa. Since 1998, he has headed the research group 'Environmental Biochemistry' in the Department of Environmental Microbiology at Eawag. His primary research interests include microbial degradation and environmental fate of recalcitrant organic pollutants, biochemistry of mono- and dioxygenases, and microbial transformation of chiral compounds. In particular, elucidation of microbial degradation pathways, isolation and characterization of competent microbes, and identification and characterization of key enzymes are his central research themes. His research also includes the development of bioremediation strategies for decontamination of polluted sites and to promote biotechnological processes for sustainable production of organic compounds.

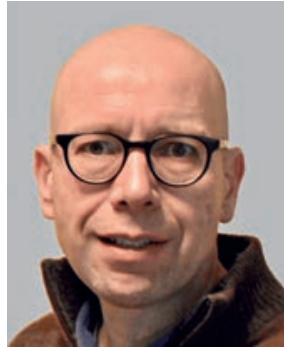

Thomas Hofstetter is a senior scientist at the Department of Environmental Chemistry at Eawag, Privatdozent (lecturer) in Environmental Chemistry at ETH Zurich, and an associated editor for the journal Environmental Science \& Technology. He obtained his $\mathrm{PhD}$ in Environmental Chemistry under the supervision of René Schwarzenbach from ETH Zurich. He was a postdoctoral researcher at the Woods Hole Institution of Oceanography and visiting scientist at the University of Minnesota. His research group studies the mechanisms and isotope effects of organic contaminant transformation processes, stable-isotope based methods to track such reactions in aquatic and soil environments, as well as the redox properties of iron-bearing minerals.

\section{Introduction}

Enzymatic oxygenations initiate biotransformation and -degradation processes of a wide range of organic contaminants. ${ }^{[1]}$ Pesticides, pharmaceuticals, fuels, explosives, and numerous other compounds undergo oxygenation in natural environments including soils, groundwaters, and surface waters or in engineered systems such as sewage treatment plants..$^{[1,2]}$ The insertion of oxygen atoms from molecular $\mathrm{O}_{2}$ usually makes organic contaminants more polar and more bioavailable thus enabling further transformation of the oxygenated products in common metabolic pathways. ${ }^{[3,4]}$ Even though such oxygenation reactions are wellknown and topics in chemistry textbooks, ${ }^{[1,4,5]}$ quantifying the rates of oxidative contaminant removal as well as the extent of oxygenation remain unresolved challenges. One of those challenges arises from the complex kinetic mechanisms of enzymatic $\mathrm{O}_{2}$ activation and formation of electrophilic oxygen species. 
Enzymes use very different strategies to overcome the thermodynamic and kinetic obstacles associated with the endergonic first electron transfer to $\mathrm{O}_{2}$ and spin restriction for reactions of the $\mathrm{O}_{2}$ triplet ground state. ${ }^{[6-8]}$ General relationships between the structure and electronic properties of the oxygenated substrates and their reactivity towards enzymatic oxygenation are therefore difficult to obtain. Current evidence suggests that highly recalcitrant compounds including (poly)aromatic hydrocarbons, chlorinated biphenyls, and nitroarenes are oxygenated by transition metalcontaining enzymes where $\mathrm{O}_{2}$ is activated at non-heme ferrous iron centers. Conversely, heme-bound ferrous iron, as found in cytochrome $\mathrm{P} 450,{ }^{[9,10]}$ appears to be involved primarily in the hydroxylation of aliphatic hydrocarbon and activated aromatic moieties including substituted phenols, methylbenzene, and $\mathrm{N}$-alkyl amines and thus react with the less persistent organic contaminants compared to non-heme iron oxygenases. The same type of reactive moieties can also be hydroxylated by oxygenases where reactive $\mathrm{O}_{2}$ arises through electron transfer from reduced flavins without any transition metal cofactor.

Knowing the type of oxygenase responsible for organic contaminant transformation is one of several crucial factors for assessing the macroscopically observable rates of oxidative contaminant turnover besides, for example, substrate bioavailability, microbial growth, etc. ${ }^{[1]}$ Moreover, the elementary reactions leading to substrate oxygenation are not necessarily the rate-determining steps of catalytic cycles. In transition metal-containing oxygenases as well as flavin-dependent oxygenases, substrate binding is frequently required for $\mathrm{O}_{2}$ activation and the reduction of $\mathrm{O}_{2}$ to superoxo-, peroxo-, or oxo-species often exhibits the highest activation barrier. ${ }^{[11]}$ Such catalytic strategies imply that the rate of contaminant transformation is not determined by the hydroxylation reaction and thus precludes an assessment of contaminant reactivity from the electronic properties of the oxidizable structural moieties of contaminants. Moreover, oxygenases also react along unproductive pathways where the activated oxygen states yield reactive oxygen species without substrate metabolism. ${ }^{[7,8,12]}$ This $\mathrm{O}_{2}$ uncoupling is studied traditionally to understand the formation and consequences of cytotoxic reactive oxygen species ${ }^{[13]}$ whereas the consequences of $\mathrm{O}_{2}$ uncoupling for the oxidative turnover of substrate have been only of minor scientific interest. This overlooked aspect of an oxygenase's catalytic cycle, however, appears quite relevant for quantifying organic contaminant biotransformation and -degradation.

The goal of this review is to identify the critical features of the catalytic cycles of selected oxygenases which could determine rates and extents of biodegradation of organic contaminants. Our discussion will focus on non-heme ferrous iron oxygenase ${ }^{[14]}$ because of the versatility of the catalyzed reactions as well as practical relevance for the transformation of some of the most recalcitrant aromatic contaminants. The current state of knowledge for this family of enzymes also offers an excellent opportunity to illustrate the different strategies of reductive $\mathrm{O}_{2}$ activation and to elucidate the roles of cosubstrates and $\mathrm{O}_{2}$ for the kinetics of organic contaminant transformation.

\section{Catalytic Strategies of Mononuclear Non-heme Ferrous Iron (Di)oxygenases}

Mononuclear non-heme ferrous iron (di)oxygenases represent a growing class of enzymes that share a structural motif consisting of two histidine and one carboxylate residue as the 2-His-1carboxylate facial triad for binding catalytically active iron in the active site. ${ }^{[14-17]}$ This iron coordination enables the binding of up to three additional ligands including substrate, organic cofactors, and molecular $\mathrm{O}_{2}$ and is responsible for the versatility of the nonheme ferrous oxygenases in catalyzing important metabolic oxygenations and oxidations. The biochemical aspects of these reactions as well as the identity and features of the reactive Fe-oxygen species have been elucidated in great detail and this information is compiled in numerous excellent and comprehensive reviews (for example refs [14-25]). By contrast, many kinetic aspects that would be highly relevant for assessing the rates and efficiency of contaminant oxygenation remain elusive. The opportunity to bind several ligands at the 2-His-1-carboxylate facial triad also gives rise to different catalytic scenarios for the functioning of mononuclear non-heme ferrous oxygenases. As will be discussed in the following, different sequences for the binding of substrate, co-substrate, and $\mathrm{O}_{2}$ are possible. These sequences also determine the timing and type of $\mathrm{Fe}$ coordination changes, $\mathrm{O}_{2}$ activation, as well as substrate oxygenation, and they are thus responsible for the rate-determining steps of a catalytic cycle.

Here, we categorize the catalytic cycles of mononuclear nonheme ferrous oxygenases according to their strategies for the four electron reduction of $\mathrm{O}_{2}$, which also reflects the timing of kinetically relevant substrate interactions. While two electrons are always supplied through substrate oxidation, another two electrons originate either from the substrate, directly from organic cofactors, or they are supplied through an electron transport chain. In our schematic illustrations of the catalytic cycles in Fig. 1, we deliberately omit chemically relevant details such as Fe oxidation states and the identity of activated oxygen species for simplicity. Those details will be discussed exemplarily in the following chapter.

Substrate-chelating oxygenases such as extradiol dioxygenase, ${ }^{[17]}$ isopenicillin $\mathrm{N}$ synthase, 2-hydroxyethylphosphonate dioxygenase, ${ }^{[26]}$ and 1-aminocyclopropane-1-carboxylate oxidase ${ }^{[14]}$ carry out four electron oxidations of their substrates. Catalytic cycles of this group of oxygenases are initiated through the chelation of substrate ligands to the catalytic Fe center in the resting state of the enzyme (Fig. 1a). Substrate chelation triggers the binding and activation of $\mathrm{O}_{2}$ at the metal center. This step is followed by electron transfer between the substrate and oxygen, leading to $\mathrm{O}-\mathrm{O}$ bond cleavage and, finally, substrate hydroxylation. The resting state is re-established after product release without any external electron source. ${ }^{[17]}$

Cosubstrate-dependent oxygenases retrieve two electrons from the substrate and another two electrons from an organic cosubstrate such as 2-oxo acids ( $\alpha$-ketoglutarate-dependent oxygenases) or tetrahydropterin (tetrahydropterin-dependent hydroxylases) present in the active site. $\alpha$-Ketoglutarate-dependent oxygenases are involved in the degradation of the herbicide 2-(4-chloro-2-methylphenoxy)propionic acid (mecoprop). ${ }^{[27,28]}$ Fig. 1b shows the catalytic cycle of $\alpha$-ketoglutarate-dependent oxygenases where the catalytic $\mathrm{Fe}$ is chelated by the 2-oxo acid in the resting state. The substrate enters the active site before $\mathrm{O}_{2}$ activation at the metal center but it is not coordinated directly to the catalytic Fe. Activated oxygen species first lead to the decarboxylation of $\alpha$-ketoglutarate thereby generating a high-valent oxygen species capable of $\mathrm{H}$ atom abstraction followed by a rebound of the hydroxyl radical to form the hydroxylated product. The release of succinate and the hydroxylated product and regeneration of $\alpha$-ketoglutarate return the enzyme to its resting state.

Rieske dioxygenases obtain two electrons from the aromatic substrate while two additional electron equivalents from NADH oxidation are supplied by electron transfer proteins via the eponymous Rieske cluster. Analogous to cosubstrate-dependent oxygenases, the organic substrate is not coordinated to the metal center in Rieske dioxygenases (Fig. 1c). The presence of the substrate at the active site is prerequisite for $\mathrm{O}_{2}$ binding and activation by oxidation of the ferrous iron while a second, external electron is transferred from a [2Fe-2S] Rieske cluster. The ensuing $\mathrm{Fe}$ oxygen species are capable of dihydroxylating unactivated aromatic rings. Further electron transfer via the Rieske cluster to the catalytic Fe and product release are required to re-establish the enzyme's resting state. 
(a) Substrate-chelating oxygenases

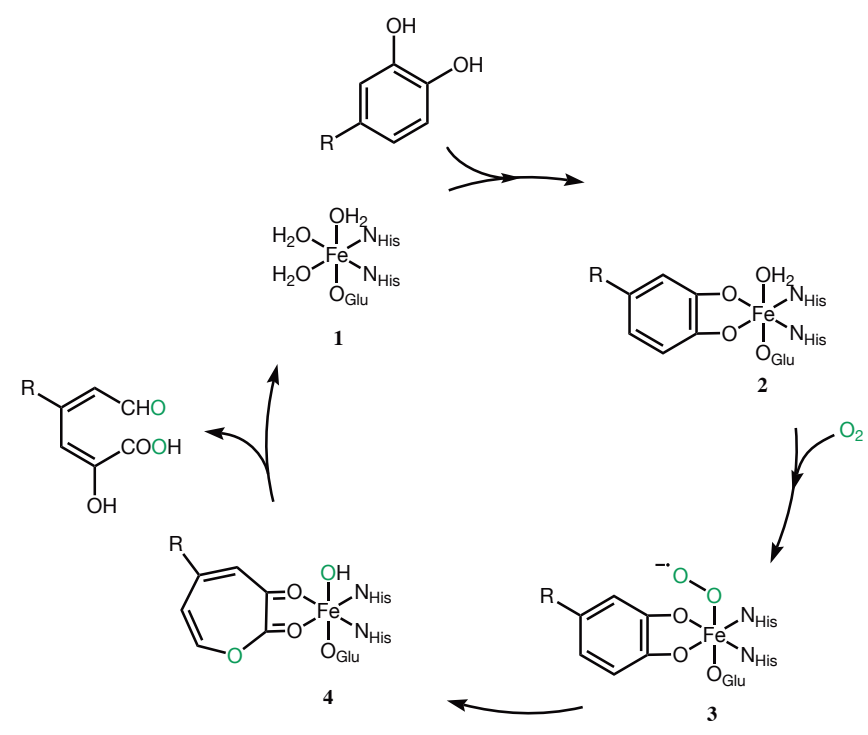

(b) Cosubstrate-dependent oxygenases
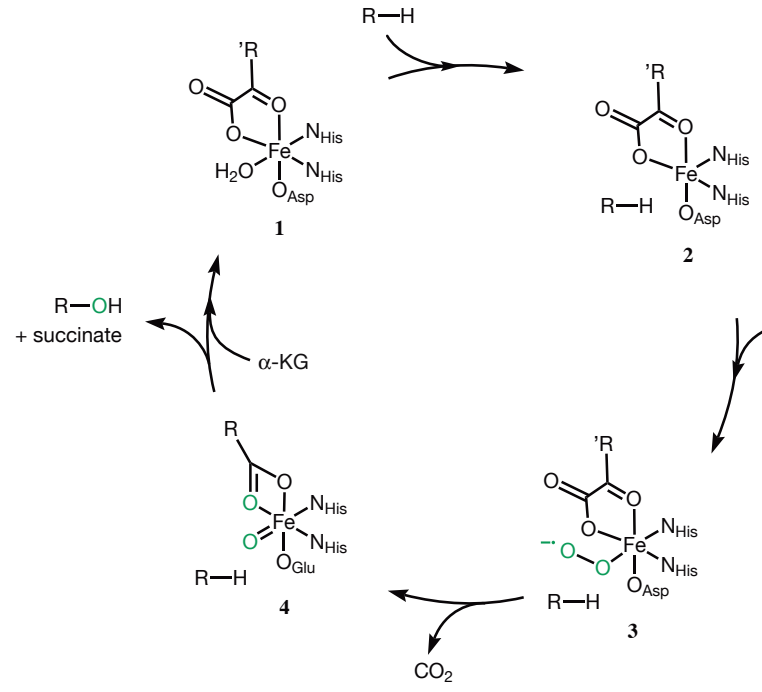

(c) Rieske dioxygenases

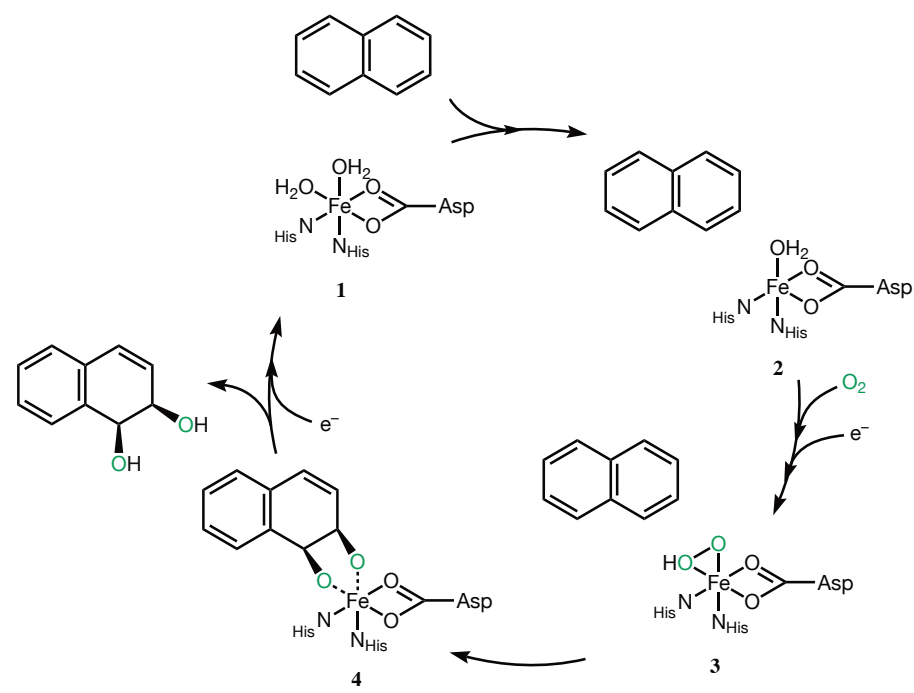

Fig. 1. Catalytic cycles of representatives of (a) substrate-chelating oxygenases (extradiol dioxygenase), (b) cosubstrate-dependent oxygenases ( $\alpha$-ketoglutarate-dependent oxygenases), and (c) Rieske dioxygenases (naphthalene dioxygenase). Species' labels indicate 1 resting state, 2 change in Fe coordination after substrate binding, $\mathbf{3}$ activated Feoxygen species, and 4 substrate hydroxylation. ${ }^{[14,17]}$ Note that Fe redox states and electron balances have been omitted for simplicity.
The catalytic cycles of mononuclear non-heme ferrous iron oxygenases shown in Fig. 1 illustrate that the association of the organic substrate with the active site of the enzyme is key to initiate $\mathrm{O}_{2}$ activation. However, these interactions of the substrate with the catalytic $\mathrm{Fe}$ and activated Fe-oxygen species follow different kinetic mechanisms. Several chemically distinct elementary reactions precede organic substrate hydroxylation and could thus contribute to the observable rate of substrate disappearance. As we will discuss in detail in the next section for Rieske dioxygenases, information on the catalytic mechanisms is scarce thus limiting a general interpretation of substrate-specific enzyme activity.

\section{Catalytic Cycles and Kinetic Mechanisms of Rieske Dioxygenases}

Rieske dioxygenases catalyze the cis-dihydroxylation of aromatic compounds and are thus particularly relevant for the biodegradation of persistent organic contaminants. The various members of the subfamily of Rieske dioxygenases have been classified according to the similarity of their catalytic oxygenase $\alpha$-subunit and include the naphthalene, benzoate, toluene/biphenyl, and the phthalate subfamilies. ${ }^{[29]}$ The catalytic cycle of Rieske dioxygenases is characterized by the electron transfer between the [2Fe-2S] Rieske cluster and the non-heme mononuclear iron center which are located in two adjacent $\alpha$-subunits of the oxygenase and connected through an aspartate (Asp) residue (see Fig. 2 for the example of naphthalene dioxygenase, naphthalene-DO ${ }^{[30-33]}$ ). In addition to providing electrons for $\mathrm{O}_{2}$ activation, the oxidation states of the Rieske cluster, that is (fully) oxidized, $\mathrm{Fe}^{\mathrm{III}}-\mathrm{Fe}^{\mathrm{III}}$, and (partially) reduced $\mathrm{Fe}^{\mathrm{III}}-\mathrm{Fe}^{\mathrm{II}}$, trigger conformational changes and thereby modulate the distance between the catalytic non-heme iron and the substrate and thus the reactivity of activated $\mathrm{Fe}$ oxygen species. Even though Rieske dioxygenases all share these catalytic features, the kinetic mechanisms, especially with regard to the rate-determining steps of the catalytic cycles, seem to vary among different enzymes. While endergonic steps of $\mathrm{O}_{2}$ activation have been postulated as kinetic bottlenecks for naphthalene-DO, evidence for other Rieske dioxygenases, such as benzoate dioxygenase (benzoate-DO), suggest a rate-determining substrate hydroxylation. A general interpretation of the catalytic mechanisms of Rieske dioxygenases is limited because only few studies describe the overall catalytic cycle comprehensively. Here, we will discuss naphthalene-DO and benzoate-DO as two of these welldocumented examples to illustrate the current state-of-knowledge.

\subsection{Rate-determining Steps}

The resting state of the oxygenase component of naphthalene-DO and its active site structure are characterized by the reduced iron oxidation states. Non-heme $\mathrm{Fe}^{\mathrm{II}}$ is 6-coordinate with two histidines, one bidentate aspartate, and two solvent (water) molecules (Fig. 2, 1). ${ }^{[34,36]}$ The reduced Rieske cluster is in the proximity of the catalytic iron and only this configuration enables substrate binding in the active site pocket. ${ }^{[34,35,37,38]}$ The presence of naphthalene triggers the removal of one water ligand leading to a coordinatively unsaturated, 5-coordinate catalytic $\mathrm{Fe}^{\mathrm{II}}$ which is then available for the side-on binding of $\mathrm{O}_{2}(2) .{ }^{[32,39,40]}$ The following electron transfers from non-heme $\mathrm{Fe}^{\mathrm{II}}{ }^{2}$ and the reduced Rieske cluster give rise to activated $\mathrm{Fe}$-oxygen species as $\mathrm{Fe}^{\mathrm{III}}$-superoxo (3a), Fe ${ }^{\mathrm{III}}$-peroxo (3b), and $\mathrm{Fe}^{\mathrm{V}}$-oxo species (3c). Oxidation of the Rieske cluster $(\mathbf{3 a} \rightarrow \mathbf{3 b})$ is also accompanied by the elimination of another water molecule, a change in the coordination geometry of the catalytic ferrous site, and a decrease of the distance between the catalytic $\mathrm{Fe}$ and the substrate. ${ }^{[14,17,34,40,41]}$ Species $\mathbf{3 b}$ and $\mathbf{3 c}$ are responsible for naphthalene dihydroxylation (4) to the cisdihydrodiol product and different mechanisms for stepwise vs. concerted hydroxylations have been proposed which we do not show in Fig. 2. ${ }^{[23]}$ The catalytic cycle is completed through the reduction of the non-heme Fe and the Rieske cluster with electron 


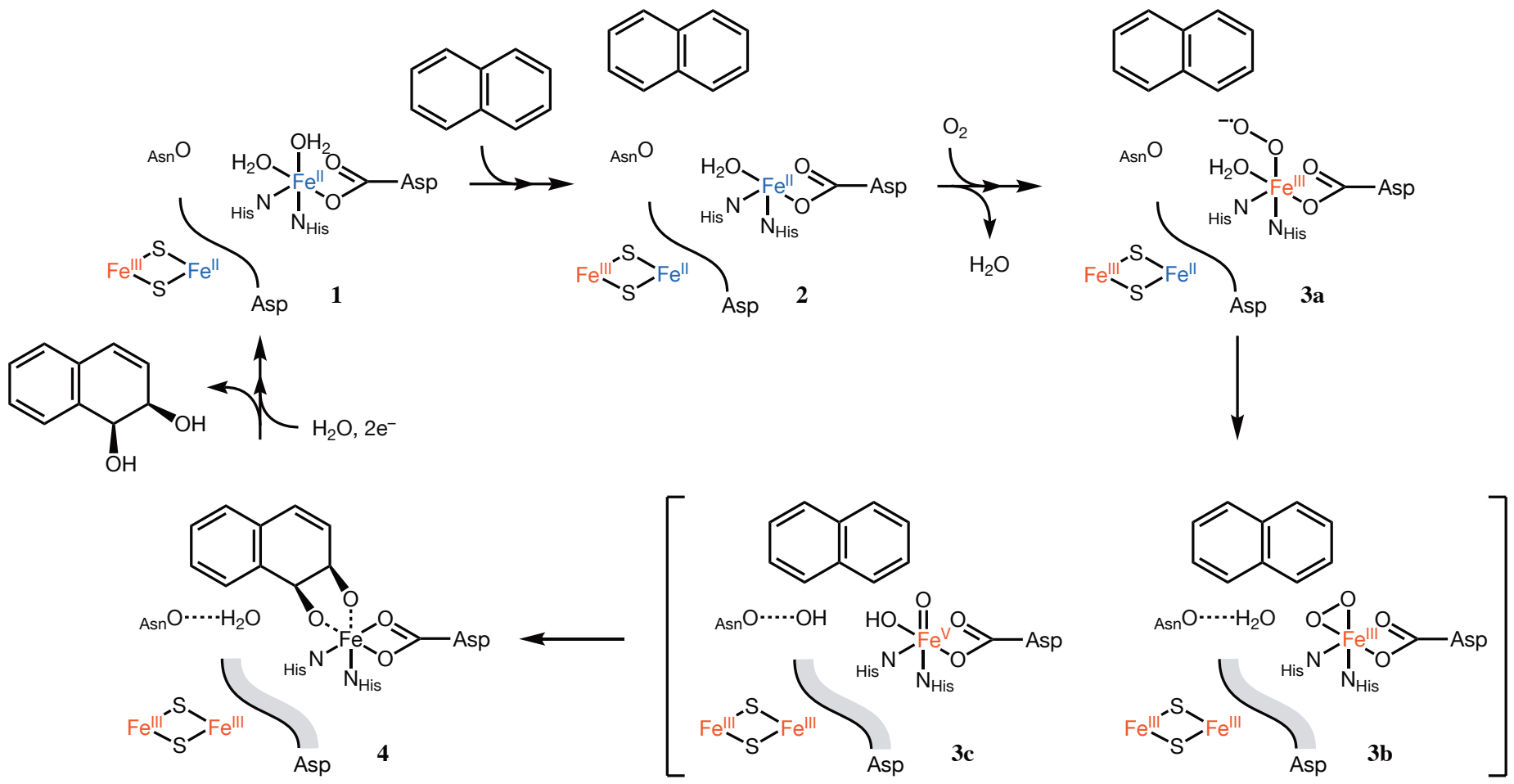

Fig. 2. Simplified catalytic cycle of naphthalene dioxygenase (naphthalene-DO) as representative for Rieske dioxygenases. ${ }^{[17,34,35]}$ The curved line between the [2Fe-2S] Rieske cluster and the non-heme iron center represents the boundary between adjacent $\alpha$-subunits of the enzyme that are bridged by an Asp residue. The ${ }_{\text {Asn }} \mathrm{O}$ residue coordinates one of the $\mathrm{H}_{2} \mathrm{O}$ ligands of the non-heme iron center. Brackets stand for the different reactive Fe-oxygen species hypothesized for cis-dihydroxylation by naphthalene-DO. Labels 1 to 4 represent the same stages within the catalytic cycle as in Fig. 1.

equivalents from NADH transferred via the reductase and ferredoxin component of naphthalene-DO.

The assignment of rate-determining steps in the catalytic cycle of naphthalene-DO is still controversial and closely related to the hypotheses regarding the type of reactive Fe-oxygen species in reactions $3 \mathbf{b} / \mathbf{3 c} \rightarrow \mathbf{4}$. Concerted dihydroxylation by high-valent $\mathrm{Fe}^{\mathrm{V}}$-oxo species $(\mathbf{3 c})$ requires a cleavage of $\mathrm{O}-\mathrm{O}$ bonds prior to naphthalene oxygenation. Theoretical work shows that this step exhibits high activation barriers ${ }^{[42-44]}$ and would imply a dominant contribution of $\mathrm{O}_{2}$ activation to the kinetics of substrate hydroxylation. Conversely, naphthalene hydroxylation from $\mathrm{Fe}^{\mathrm{III}}$-peroxo species (3b) through epoxides or iron-peroxy-naphthalene radical intermediates allow for scenarios where substrate hydroxylation is sufficiently endergonic to be at least partly rate-determining. Based on these ambiguities for a kinetic mechanism of naphthalene-DO, substrate hydroxylation could be reflected in the rate of substrate transformation but the contribution of this reaction remains unclear.

A different kinetic mechanism has been proposed for benzoate-DO in which reactions of the substrate with $\mathrm{Fe}^{\text {III }}$ superoxo species (3a) are considered rate-determining. [38,45] The fundamental difference to previous interpretations of the catalytic cycle of Rieske dioxygenases is that the first substrate oxygenation reaction catalyzed by benzoate-DO occurs prior to the electron transfer from the reduced Rieske cluster to the non-heme Fe ${ }^{\mathrm{III}}$-superoxo species. Substrate oxygenation by Fe $\mathrm{Fe}_{\text {II }}$ superoxo species does not require prior cleavage of $\mathrm{O}-\mathrm{O}$ bonds. In this kinetic mechanism, the first substrate oxygenation step is potentially rate-determining while the subsequent addition of the second oxygen atom to a substrate epoxide intermediate is considered to occur much faster. Rivard et al. ${ }^{[45]}$ arrive at this conclusion also through correlations of decreasing Rieske cluster oxidation rates with decreasing partial charges at the carbon moieties of fluorobenzoate substrates that are susceptible to hydroxylation. The interpretation of a rate-determining Rieske oxidation concomitant with substrate hydroxylation is further supported by ob- servations that the reduction potentials of the catalytic non-heme $\mathrm{Fe}^{\mathrm{III}}$ is more than $200 \mathrm{mV}$ lower than that of $\mathrm{Fe}^{\mathrm{III}}$ in the Rieske cluster and that the latter is a less potent reductant.[46]

\section{$3.2 \mathrm{O}_{2}$ Uncoupling}

The extent of oxidative contaminant turnover by Rieske dioxygenases is also limited by unproductive activation of $\mathrm{O}_{2}$ and release as reactive oxygen species. This so-called $\mathrm{O}_{2}$ uncoupling reduces the effective specific activity of oxygenases and complicates the assessment of rates of hydroxylation. Indirect observations of $\mathrm{O}_{2}$ uncoupling through oxidative stress responses towards oxygenase activity illustrate the prevalence of the phenomenon ${ }^{[47,48]}$ but very few studies have quantified uncoupling of Rieske dioxygenases systematically. The data in Table 1 illustrate the substrate specificity of the extent of uncoupling ranging from non-detectable levels to complete uncoupling of the activated $\mathrm{O}_{2} \cdot{ }^{[49]}$ Native substrates are hypothesized to show the lowest degree of $\mathrm{O}_{2}$ uncoupling. In fact, for the oxygenation of naphthalene by naphthalene-DO, biphenyl by biphenyl-dioxygenase (biphenyl-DO), and dibenzofuran by dibenzofuran-dioxygenase (dibenzofuran-DO), uncoupling is $0 \%, 3 \%$, and $17 \%$, respectively (Table 1). These moderate contributions of nonproductive $\mathrm{O}_{2}$ activation for the native substrate of these three Rieske dioxygenases appear reasonable given that these substances are hydroxylated in metabolic pathways of the host cell as sole carbon and energy source. Conversely, turnover of benzene and toluene by naphthalene-DO and dichlorobiphenyls by biphenyl-DO releases $30 \%$ to $70 \%$ of activated $\mathrm{O}_{2}$ as $\mathrm{H}_{2} \mathrm{O}_{2}$. Exposure of dibenzofuran-DO to naphthalene led to complete $\mathrm{O}_{2}$ uncoupling. ${ }^{[49]}$ These observations suggest that alternative substrates with molecular structures that resemble those of the native substrates can also trigger $\mathrm{O}_{2}$ binding and activation but an imperfect fit to the active site pocket may prevent hydroxylation.

In the context of contaminant biodegradation, however, where contaminants are often present as mixtures of structurally related compounds, this interpretation could be overly simplistic and not 
Table 1. Survey of quantitative estimates of $\mathrm{O}_{2}$ uncoupling for mononuclear non-heme ferrous iron oxygenases. Uncoupling is presented as the ratio of excess $\mathrm{O}_{2}$ consumption relative to substrate consumption or hydroxylated product formation.

\begin{tabular}{|c|c|c|c|}
\hline Enzyme & Substrate & Uncoupling & Ref. \\
\hline \multicolumn{4}{|l|}{ Rieske dioxygenases } \\
\hline \multirow[t]{4}{*}{ Naphthalene-DO } & naphthalene & $0 \%$ a & {$[51]$} \\
\hline & benzene & $40-50 \%{ }^{\mathrm{a}}$ & \\
\hline & naphthalene & $0 \%$ & {$[52]$} \\
\hline & toluene & $30 \%$ & \\
\hline \multirow[t]{4}{*}{ Biphenyl-DO } & biphenyl & $3 \%$ & {$[53]$} \\
\hline & 2,2'-dichlorobiphenyl & $66 \%$ & \\
\hline & 3,3'-dichlorobiphenyl & $37 \%$ & \\
\hline & 4,4'- dichlorobiphenyl & $52 \%$ & \\
\hline \multirow[t]{2}{*}{ Dibenzofuran-DO } & dibenzofuran & $17 \%$ & {$[49]$} \\
\hline & naphthalene & $100 \%$ & \\
\hline \multicolumn{4}{|c|}{ Substrate-chelating oxygenases } \\
\hline \multirow[t]{3}{*}{$\mathrm{ACCO}^{\mathrm{b}}$} & $\mathrm{ACC}^{\mathrm{c}}$ & $15-31 \%$ & {$[54]$} \\
\hline & $\mathrm{ACC}-\mathrm{NH}_{2}{ }^{\mathrm{d}}$ & $77 \%$ & \\
\hline & glycine & $95 \%$ & \\
\hline \multicolumn{4}{|c|}{ Cosubstrate-dependent oxygenases } \\
\hline \multirow[t]{2}{*}{ Phenylalanine-hydroxylase } & phenylalanine & $3 \%$ & {$[55]$} \\
\hline & 4-chlorphenylalanine & $49 \%$ & \\
\hline
\end{tabular}

aRatio of $\mathrm{H}_{2} \mathrm{O}_{2}$ formed to $\mathrm{O}_{2}$ consumed; ${ }^{\text {b }}$-aminocyclopropane-1-carboxylic acid oxidase; ${ }^{\mathrm{c}}$ 1-aminocyclopropane-1-carboxylic acid; ${ }^{\mathrm{d}} 1$-aminocyclopropane-1-carboxamide.

account for adaptive responses to oxidative stress. Faulty oxygenations induce mutations and exert a selective pressure that could potentially accelerate the evolution of enzymes with an adapted substrate range as shown for Rieske dioxygenases. ${ }^{[48]}$ For example, incubations with 3-nitrotoluene isomers as substrates for 2-nitrotoluene-2,3-dioxygenase of Acidovorax sp. strain JS42 induced mutations in the gene encoding the $\alpha$-subunit even after short exposure times. ${ }^{[50]}$ Those mutations of the enzymes enhanced the affinities and catalytic efficiencies towards the non-native substrate. Unfortunately, none of these works included a quantification of the extent of $\mathrm{O}_{2}$ uncoupling.

\section{Rate-Determining Steps and $O_{2}$ Uncoupling in Reactions of Other Non-heme Ferrous Iron Oxygenases}

The principles for the interpretations of the catalytic cycles shown above for Rieske dioxygenases apply in a similar manner to substrate-chelating and cosubstrate-dependent non-heme ferrous iron oxygenases. Formation of higher-valent Fe-oxygen species in Rieske dioxygenases requires a larger degree of $\mathrm{O}-\mathrm{O}$ bond cleavage prior to substrate hydroxylation thus making the $\mathrm{O}_{2}$ activation contribute more prominently to the rate-determining steps of substrate transformation. By contrast, stepwise dioxygenations initiated from $\mathrm{Fe}^{\mathrm{III}}$-superoxo-species allow for a concurrent $\mathrm{O}_{2}$ activation and substrate hydroxylation to be rate-determining. While a comprehensive evaluation of the catalytic cycles of non-heme ferrous iron oxygenases is beyond the scope of this work, in the following we discuss examples for substrate-chelating enzymes to illustrate some of the current methodologies used for unravelling the kinetic complexity of their reactions and to compare the limited quantitative evidence for $\mathrm{O}_{2}$ uncoupling.

The oxygenation of 2-hydroxyethylphosphonate by 2-hydroxyethylphosphonate dioxygenase and methylphosphonate synthase and the ensuing $\mathrm{C}-\mathrm{C}$ bond cleavage provide four electrons for the reduction of $\mathrm{O}_{2}$ without exogenous reductant. ${ }^{[26,56]}$ To probe for the timing of $\mathrm{O}_{2}$ activation to $\mathrm{Fe}^{\mathrm{III}}$-superoxo species vs. the initial $\mathrm{H}$ atom abstraction from the substrate, Zhu et al. ${ }^{[56]}$ evaluated a combination of substrate and co-substrate isotope effects. The magnitude of the ${ }^{18} \mathrm{O}$-kinetic isotope effects (KIE) provided evidence for the changes of $\mathrm{O}-\mathrm{O}$ bonding up to the rate-limiting step of $\mathrm{O}_{2}$ activation. ${ }^{[57,58]}$ Experiments with unlabeled and ${ }^{2} \mathrm{H}$-labelled substrate allowed for an assessment of the kinetic contribution of the $\mathrm{H}$ atom abstraction reaction in the kinetic mechanism. Because ${ }^{18} \mathrm{O}$-KIEs were sensitive to the ${ }^{2} \mathrm{H}$ label, the authors concluded that the initial $\mathrm{H}$ atom abstraction from 2-hydroxyethylphosphonate happened either prior to or concomitant with $\mathrm{O}_{2}$ reduction to the $\mathrm{Fe}^{\mathrm{III}}$-superoxo species. This example suggests that the study of isotope effects in oxygenation reactions, which are done to elucidate contaminant biodegradation, ${ }^{[59]}$ could also provide valuable information on the kinetic mechanisms of organic contaminant oxygenations.

Selected examples shown in Table 1 show that the phenomenon of $\mathrm{O}_{2}$ uncoupling is also found in substrate-chelating and cosubstrate-dependent oxygenases and that its extent is again substrate-specific. Similar to Rieske dioxgenases, 1-aminocyclopropane 1-carboxylic acid oxidase (ACCO) oxidizes its native substrates most efficiently, whereas structurally similar substrates 
such as the carboxamide cause significant uncoupling. ${ }^{[54,55]}$ The uncoupling behavior of tetrahydropterin-dependent phenylalanine hydroxylase is particularly interesting because this physiologically and evolutionary ancient oxygenase is rarely exposed to alternative substrates. Indeed, phenylalanine causes almost no uncoupling whereas the presence of 4-chloro-substituted phenylalanine leads to $\mathrm{O}_{2}$ uncoupling of $49 \%$. ${ }^{[55]}$

\section{Conclusions and Outlook}

This compilation of the kinetic mechanisms pertinent to the catalytic cycles of mononuclear non-heme ferrous iron oxygenases shows that knowledge of the rate-limiting steps and the extent of $\mathrm{O}_{2}$ uncoupling is critical to understand rates and extents of organic contaminant biotransformation and -degradation. Even though mechanistic studies in enzymology performed over the last decades provide detailed descriptions of the catalytic cycles, information for assessing organic contaminant biotransformation by oxygenases is scarce.

Current knowledge for contaminant oxygenation by Rieske dioxygenases including naphthalene-, nitrobenzene-, and several nitrotoluene-dioxygenases show that these enzymes exhibit a broad substrate spectrum. ${ }^{[36,48]}$ Unfortunately, experimental and computational data ${ }^{[60,61]}$ for contaminant-degrading oxygenases do not allow for inferences of the kinetic mechanisms of these oxygenases and the relevance of $\mathrm{O}_{2}$ activation vs. substrate hydroxylation reaction is unknown. Further work on enzymatic contaminant oxygenation should therefore include systematic kinetic analyses of a wider range of structurally related substrates and organic contaminants in combination with the study of substrate and cosubstrate isotope effects as shown for selected examples above. ${ }^{[45,56-58]}$ In fact, recent work on substrate isotope effects associated with the oxygenation of organic compounds by flavindependent monooxygenases ${ }^{[62]}$ and Rieske dioxygenases ${ }^{[63,64]}$ revealed variable contributions of substrate hydroxylation to the rate-determining steps of a catalytic cycle. Future studies should also be accompanied by the quantification of substrate-specific $\mathrm{O}_{2}$ uncoupling to account for the evolutionary responses to oxidative stress.

Received: December 22, 2019

[1] R. P. Schwarzenbach, P. M. Gschwend, D. M. Imboden, 'Environmental Organic Chemistry', John Wiley \& Sons, 3rd Edn., 2017.

[2] R. A. Larson, E. J. Weber, 'Reaction Mechanisms in Environmental Organic Chemistry', Lewis Publishers, 1994.

[3] G. Fuchs, M. Boll, J. Heider, Nat. Rev. Microbiol. 2011, 9, 803, doi: 10.1038/ nr.micro2652.

[4] T. D. H. Bugg, D. R. Boyd, 'Introduction to Enzyme and Coenzyme Chemistry', Blackwell Publishing Ltd, 3rd Edn., 2012.

[5] A. H. Neilson, A.-S. Allard, 'Environmental Degradation and Transformation of Organic Chemicals', CRC Press, 2008

[6] H.-P. E. Kohler in 'Biophysico-chemical processes of anthropogenic organic compounds in environmental systems', Eds. B. Xing, N. Senesi, P. M. Huang; John Wiley \& Sons, Inc., Hoboken, NJ, USA, 2011, p. 463.

[7] I. Bertini, H. B. Gray, E. I. Stiefel, J. Selverstone Valentine, 'Biological Inorganic Chemistry - Structure and Reactivity', University Science Books, 2007.

[8] J. Selverstone Valentine, C. S. Foote, A. Greenberg, J. F. Liebman, 'Active Oxygen in Biochemistry', Chapman \& Hall, Dordrecht, 1995.

[9] I. Denisov, T. Makris, S. Sligar, I. Schlichting, Chem. Rev. 2005, 105, 2253, doi: $10.1021 / \mathrm{cr} 0307143$.

[10] J. P. T. Zaragoza, D. P. Goldberg in 'Dioxygen-dependent Heme Enzymes', Eds. M. Ikeda-Saito, E. Raven, Royal Society of Chemistry, 2018, p. 1.

[11] B. A. Palfey, C. A. McDonald, Arch. Biochem. Biophys. 2010, 493, 26, doi 10.1016/j.abb.2009.11.028

[12] Y. V. Grinkova, I. G. Denisov, M. A. McLean, S. G. Sligar, Biochem Biophys. Res. Commun. 2013, 430, 1223, doi: 10.1016/j.bbrc.2012.12.072.

[13] J. P. Klinman, Acc. Chem. Res. 2007, 40, 325, doi: 10.1021/ar6000507.

[14] S. Kal, L. Que, J. Biol. Inorg. Chem. 2017, 22, 339, doi: 10.1007/s00775016-1431-2.
[15] P. C. A. Bruijnincx, G. van Koten, R. J. M. Klein Gebbink, Chem. Soc. Rev. 2008, 37, 2716, doi: 10.1039/b707179p.

[16] E. I. Solomon, T. C. Brunold, M. I. Davis, J. N. Kemsley, S. K. Lee, N. Lehnert, F. Neese, A. J. Skulan, Y. S. Yang, J. Zhou, Chem. Rev. 2000, 100, 235, doi: 10.1021/cr9900275.

[17] E. G. Kovaleva, J. D. Lipscomb, Nat. Chem. Biol. 2008, 4, 186, doi: 10.1038/ nchembio.71.

[18] M. Costas, M. Mehn, M. Jensen, L. Que, Chem. Rev. 2004, 104, 939, doi: $10.1021 / \mathrm{cr} 020628 \mathrm{n}$

[19] E. I. Solomon, K. M. Light, L. V. Liu, M. Srnec, S. D. Wong, Acc. Chem. Res. 2013, 46, 2725, doi: 10.1021/ar400149m.

[20] E. G. Kovaleva, M. B. Neibergall, S. Chakrabarty, J. D. Lipscomb, Acc. Chem. Res. 2007, 40, 475, doi: 10.1021/ar700052v.

[21] J. M. Bollinger Jr, C. Krebs, Curr. Opin. Chem. Biol. 2007, 11, 151, doi: 10.1016/j.cbpa.2007.02.037

[22] C. Krebs, D. G. Fujimori, C. T. Walsh, J. M. Bollinger Jr, J. J Martin Bollinger, Acc. Chem. Res. 2007, 40, 484, doi: 10.1021/ar700066p.

[23] S. M. Barry, G. L. Challis, ACS Catal. 2013, 3, 2362, doi: 10.1021/ cs400087p.

[24] T. D. H. Bugg, S. Ramaswamy, Curr. Opin. Chem. Biol. 2008, 12, 134, doi: 10.1016/j.cbpa.2007.12.007.

[25] D. J. Ferraro, L. Gakhar, S. Ramaswamy, Biochem. Biophys. Res. Commun. 2005, 338, 175, doi: 10.1016/j.bbrc.2005.08.222.

[26] R. Cicchillo, H. Zhang, J. Blodgett, J. Whitteck, G. Li, S. Nair, W. van der Donk, W. Metcalf, Nature 2009, 459, 871, doi: 10.1038/nature07972.

[27] K. Nickel, M. J. Suter, H.-P. E. Kohler, J. Bacteriol. 1997, 179, 6674, doi: 10.1128/jb.179.21.6674-6679.1997.

[28] T. A. Müller, T. Fleischmann, J. R. van der Meer, H.-P. E. Kohler, Appl. Environ. Microbiol. 2006, 72, 4853, doi: 10.1128/AEM.02758-05.

[29] D. T. Gibson, R. E. Parales, Curr. Opin. Biotechnol. 2000, 11, 236, doi: 10.1016/S0958-1669(00)00090-2.

[30] B. Kauppi, K. Lee, E. Carredano, R. E. Parales, D. T. Gibson, H. Eklund, S. Ramaswamy, Struct. Fold. Des. 1998, 6, 571, doi: 10.1016/S09692126(98)00059-8.

[31] R. E. Parales, J. V. Parales, D. T. Gibson, J. Bacteriology 1999, 181, 1831, doi: 10.1016/S1367-5931(98)80065-3.

[32] R. E. Parales, J. Ind. Microbiol. Biotechnol. 2003, 30, 271, doi: 10.1007/ s10295-003-0043-3.

[33] D. J. Ferraro, A. Okerlund, E. Brown, S. Ramaswamy, IUCrJ 2017, 4, 648, doi: 10.1107/S2052252517008223.

[34] T. Ohta, S. Chakrabarty, J. D. Lipscomb, E. I. Solomon, J. Am. Chem. Soc. 2008, 130, 1601, doi: 10.1021/ja074769o.

[35] M. D. Wolfe, J. V. Parales, D. T. Gibson, J. D. Lipscomb, J. Biol. Chem. 2001, 276, 1945, doi: 10.1074/jbc.M007795200.

[36] R. Friemann, M. M. Ivkovic-Jensen, D. J. Lessner, C. L. Yu, D. T. Gibson, R. E. Parales, H. Eklund, S. Ramaswamy, J. Mol. Biol. 2005, 348, 1139, doi: 10.1016/j.jmb.2005.03.052.

[37] T. C. Yang, M. D. Wolfe, M. B. Neibergall, Y. Mekmouche, J. D. Lipscomb, B. M. Hoffman, J. Am. Chem. Soc. 2003, 125, 2034, doi: 10.1021/ja028781m.

[38] M. D. Wolfe, D. J. Altier, A. Stubna, C. V. Popescu, E. Munck, J. D. Lipscomb, Biochem. 2002, 41, 9611, doi: 10.1021/bi025912n.

[39] K. D. Koehntop, J. P. Emerson, L. Que, J. Biol. Inorg. Chem. 2005, 10, 87, doi: 10.1007/s00775-005-0624-X.

[40] A. Karlsson, J. V. Parales, R. E. Parales, D. T. Gibson, H. Eklund, S. Ramaswamy, Science 2003, 299, 1039, doi: 10.1126/science.1078020.

[41] M. D. Wolfe, J. D. Lipscomb, J. Biol. Chem. 2003, 278, 829, doi: 10.1074/ jbc.M209604200.

[42] A. Bassan, M. R. A. Blomberg, P. E. M. Siegbahn, J. Biol. Inorg. Chem. 2004, 9, 439, doi: 10.1007/s00775-004-0537-0.

[43] A. Bassan, M. R. A. Blomberg, T. Borowski, P. E. M. Siegbahn, J. Phys. Chem. B 2004, 108, 13031, doi: 10.1021/jp048515q.

[44] A. Bassan, M. R. A. Blomberg, T. Borowski, P. E. M. Siegbahn, J. Inorg. Biochem. 2006, 100, 727, doi: 10.1007/s00775-004-0537-0.

[45] B. S. Rivard, M. S. Rogers, D. J. Marell, M. B. Neibergall, S. Chakrabarty, C. J. Cramer, J. D. Lipscomb, Biochem. 2015, 54, 4652, doi: 10.1021/acs. biochem.5b00573

[46] H. Twilfer, F.-H. Bernhardt, K. Gersonde, Eur. J. Biochem. 1985, 147, 171, doi: 10.1111/j.1432-1033.1985.tb08733.x.

[47] M. A. Patrauchan, C. Florizone, S. Eapen, L. Gomez-Gil, B. Sethuraman, M. Fukuda, J. Davies, W. W. Mohn, L. D. Eltis, J. Bacteriol. 2007, 190, 37, doi: 10.1128/JB.01122-07.

[48] D. Pérez-Pantoja, P. I. Nikel, M. Chavarria, V. de Lorenzo, PLoS Genet. 2013, 9, e1003764, doi: 10.1371/journal.pgen.1003764.

[49] P. V. Bünz, A. M. Cook, J. Bacteriol. 1993, 175, 6467, doi: 10.1128/ jb.175.20.6467-6475.1993.

[50] K. M. Mahan, J. T. Penrod, K. S. Ju, N. Al Kass, W. A. Tan, R. Truong, J. V. Parales, R. E. Parales, Appl. Environ. Microbiol. 2015, 81, 309, doi: 10.1128/ aem.02772-14.

[51] K. Lee, J. Bacteriol. 1999, 181, 2719.

[52] K.-S. Lee, D. T. Gibson, Appl. Environ. Microbiol. 1996, 62, 3101.

[53] N. Y. R. Imbeault, L. D. Eltis, J. Biol. Chem. 2000, 275, 12430, doi: 10.1074/ jbc.275.17.12430. 
[54] J. Thrower, L. M. Mirica, K. P. McCusker, J. P. Klinman, Biochem. 2006, 45, 13108, doi: 10.1021/bi010329c

[55] T. A. Dix, S. J. Benkovic, Biochem. 1985, 24, 5839, doi: 10.1021/ bi00342a022.

[56] H. Zhu, S. C. Peck, F. Bonvin, W. A. van der Donk, J. P. Klinman, J. Am. Chem. Soc. 2015, 137, 10448, doi: 10.1021/jacs.5b03907.

[57] L. M. Mirica, J. P. Klinman, Proc. Natl. Acad. Sci. 2008, 105, 1814, doi 10.1073/pnas.0711626105.

[58] L. M. Mirica, K. P. McCusker, J. W. Munos, H.-w. Liu, J. P. Klinman, J. Am Chem. Soc. 2008, 130, 8122, doi: 10.1021/ja800265s.

[59] T. B. Hofstetter, J. Bolotin, S. G. Pati, M. Skarpeli-Liati, S. Spahr, R. S. Wijker, Chimia 2014, 68, 788, doi: 10.2533/chimia.2014.788.

[60] A. Pabis, I. Geronimo, D. M. York, P. Paneth, J. Chem. Theory Comput 2014, 10, 2246, doi: 10.1021/ct500205z.

[61] A. Pabis, I. Geronimo, P. Paneth, J. Phys. Chem. B 2014, 118, 3245, doi 10.1021/jp4076299.

[62] R. S. Wijker, S. G. Pati, J. Zeyer, T. B. Hofstetter, Environ. Sci. Technol. Lett. 2015, 2, 329, doi: 10.1021/acs.estlett.5b00254.
[63] S. G. Pati, H.-P. E. Kohler, A. Pabis, P. Paneth, R. E. Parales, T. B. Hofstetter, Environ. Sci. Technol. 2016, 50, 6708, doi: 10.1021/acs.est.5b05084.

[64] S. G. Pati, H.-P. E. Kohler, T. B. Hofstetter, Meth. Enzymol. 2017, 596, 291, doi: 10.1016/bs.mie.2017.06.044.

\section{License and Terms}

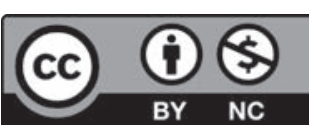

This is an Open Access article under the terms of the Creative Commons Attribution License CC BY_NC 4.0. The material may not be used for commercial purposes.

The license is subject to the CHIMIA terms and conditions: (http:// chimia.ch/component/sppagebuilder/?view = page\&id=12).

The definitive version of this article is the electronic one that can be found at doi:10.2533/chimia.2020.108 